Article

\title{
Properties of Post-Consumer Polyethylene Terephthalate Coating Mechanically Deposited on Mild Steels
}

\author{
Elisângela Silva ${ }^{1, *}$, Michele Fedel ${ }^{2}$, Flavio Deflorian ${ }^{2} \mathbb{D}$, Fernando Cotting ${ }^{1}$ and Vanessa Lins ${ }^{1}$ \\ 1 Department of Chemical Engineering, University of Minas Gerais, Av. Pres. Antônio Carlos, 6627, \\ Pampulha, Belo Horizonte 31270-901, Brazil; fernando@deq.ufmg.br (F.C.); vlins@deq.ufmg.br (V.L.) \\ 2 Department of Industrial Engineering, University of Trento, via Sommarive n. 9, 38123 Trento, Italy; \\ michele.fedel@unitn.it (M.F.); flavio.deflorian@unitn.it (F.D.) \\ * Correspondence: silvaelisangelax@gmail.com; Tel.: +55-31-3409-1737
}

Received: 16 October 2018; Accepted: 28 December 2018; Published: 5 January 2019

\begin{abstract}
An anticorrosive coating of post-consumer polyethylene terephthalate (PET) was applied on carbon steel by using an industrial press. The PET layer showed a good adhesion on the substrate, evaluated by using a pull off test, when compared with the traditional organic coatings. In addition, scanning electron microscopy (SEM) analysis showed that the PET layer was uniform, homogeneous, and free of cracks or defects. The Fourier-transform infrared spectroscopy (FTIR) and differential scanning calorimetry (DSC) proved that the PET properties were not affected by the deposition process. The PET organic coating is a promising coating, due to its corrosion resistance evaluated by using salt spray tests, even though the applied thickness of $65 \mu \mathrm{m}$ was considered thin for a high-performance coating. The electrochemical impedance spectroscopy (EIS) showed that the PET coating has a capacitive effect and its electrochemical behavior was not affected as the exposure time increased, resulting in an impedance modulus value of $10^{10} \Omega \cdot \mathrm{cm}^{2}$, after $576 \mathrm{~h}$ of immersion in an aqueous solution of $\mathrm{NaCl} 3.0 \mathrm{wt} \%$.
\end{abstract}

Keywords: corrosion; electrochemical impedance spectroscopy (EIS); organic coatings; polyethylene terephthalate (PET)

\section{Introduction}

An alternative contribution to solve the problem of urban solid waste (USW) is to use solid polymeric waste to develop coatings for steels [1]. Carbon steel has excellent mechanical properties and low cost but has some disadvantages such as low wear and corrosion resistance in various media [2]. The most employed method to protect the carbon steel against corrosion process has been the organic coatings. Polymeric layers are applied on the carbon steel to avoid the contact between metallic surface and the aggressive environment. The barrier protection conferred by the polymeric coatings can be associated to their water uptake property [3-10].

The organic coatings based on polyester, epoxy, and polyurethane resins, which present a lower water uptake value compared to alkyd resins, are widely used. Nevertheless, for long exposure time, the absorbed water reaches the metal and the corrosion process is established. In order to retard this process, thick films (from tens of $\mu \mathrm{m}$ to a few $\mathrm{mm}$ ) of these organic coatings are applied on the substrate, thus causing an increase in the total cost of this project [8-15].

Lins et al. [1] demonstrated that post-consumer commingled polymer (PCCP) coatings on carbon steels can be produced by thermal spraying and investigating their erosion behavior. Literature reports the use of post-consumer tires to develop sustainable polymeric composite materials which are 
characterized by good mechanical and functional properties [3]. Çinar and Kar [4] mixed PET waste particles in a screwed extruder with marble dust to produce a composite material.

Municipal solid waste management has received a great deal of attention as countries such as India, which produces an estimated quantity of 50-600 million tons of urban solid waste annually [5]. The municipal solid waste is mainly composed of metals, glass and plastics. The municipal solid waste of Bangalore, India, contains $6.23 \%$ of plastics [5]. In 2016, 27.1 million tons of plastic waste was collected through official schemes in the EU28 plus Norway and Switzerland to be treated, and for the first time, more plastic waste was recycled than landfilled [6].

One of the main components of plastic fraction of USW is the polyethylene terephthalate (PET) which is one of the most versatile polymers available, which makes it the most produced and used polymer worldwide $[7,8]$. PET has characteristics such as flexibility, transparency, good adhesion, low permeability to liquids and gases, high thermal resistance and low cost, all of which enable PET to be an excellent candidate for a protective coating with low thickness [8-11]. Literature reports PET deposition on steels by using low-velocity flame spray technology [9].

In this work, post-consumer PET was deposited on carbon steels by using mechanical deposition. Mechanical PET deposition presents simplicity, lower cost in relation to the thermal spraying, and was not found in literature to the best of our knowledge. The process of comminution of PET from the post-consumer bottles until a powder of the desired granulometry is not a simple process; one reason for this relies on the fact that PET is hygroscopic. Based on the obtained results, a procedure was developed for the comminution of PET from the post-consumer bottles, which has proved to be very efficient. The effect of the mechanical deposition on the PET structural and thermal properties was investigated by FT-IR spectroscopy and differential scanning calorimetry (DSC) measurements. The protection properties provided by the PET coatings were evaluated by using electrochemical impedance spectroscopy (EIS) analysis and exposure in the neutral salt spray chamber (NSST, according to the ASTM B117 [12] and ISO 9227-2017 standards [13]). The obtained results have been compared with literature data of pristine paints employed for corrosion protection purposes. In addition, adhesion tests were performed by the pull-off test, in order to characterize the interaction between PET coating and steel substrate.

\section{Materials and Methods}

\subsection{Materials}

The post-consumer PET bottles were collected from household waste; the labels and the lid were removed and discarded. The bottles were washed in soapy water. The grinding process allowed a yield of $85 \%$ of the overall use of the bottle; only the top and bottom of the bottles were not used.

The substrate used was Q-Panel type R steel with dimensions $80 \mathrm{~mm} \times 40 \mathrm{~mm} \times 1 \mathrm{~mm}$. The composition of this carbon steel was $0.15 \mathrm{C}, 0.60 \mathrm{Mn}, 0.030 \mathrm{P}, 0.035 \mathrm{~S}$ (wt \%). Prior to deposition, a blast pre-treatment of the steel samples was used, creating a roughness profile on the carbon steel surface $\left(R_{\mathrm{z}}\right)$ of approximately $20 \mu \mathrm{m}$. An SBC 350 sandblasting machine (Nova, Rehovot, Israel) was used with Garnet filter sand. After this process, the plate was washed with acetone in an ultrasonic bath for 2 min and dried with clean air.

\subsection{Deposition Process}

The amount of $0.8 \mathrm{~g}$ of PET ground with particle size of approximately $0.07 \mathrm{~mm}$ was deposited on carbon steel. The set was placed in the press for heating at $260{ }^{\circ} \mathrm{C}$ for $5 \mathrm{~min}$ without pressure; there after a pressure of 0.5 ton was applied for $2 \mathrm{~min}$. The material remained in the press and was cooled for $5 \mathrm{~min}$. The coated steel was then removed from the press and conditioned at room temperature for $24 \mathrm{~h}$. The PET coating thickness was $65 \pm 5 \mu \mathrm{m}$. 


\subsection{Coating Characterization}

The morphology of the coating was examined by using scanning electron microscopy (SEM), with a FEG-Quanta 200 FEI equipment (FEI Company, Fremont, CA, USA). The coated steel was also characterized by using Fourier transform infrared spectroscopy employing an attenuated total reflection (ATR) geometry, by means of Varian 4100 Excalibur Series equipment (Santa Clara, CA, USA). The wavelength range was $500-4000 \mathrm{~cm}^{-1}$ and the resolution of $4 \mathrm{~cm}^{-1}$. The powder and PET coating are from the same batch before and after pressing in Caver laboratory press, model 2699, Ser. No. 2699-12748, Fred S. carver Inc., Wabash, IN, USA.

The differential scanning calorimetry (DSC) test was performed using the Mettler DSC30 (Mettler Toledo, New York, NY, USA) equipment in three cycles, with heating from 0 to $300^{\circ} \mathrm{C}$ under a nitrogen flow of $10 \mathrm{~mL} \cdot \mathrm{min}^{-1}$, followed by cooling and heating from 0 to $300{ }^{\circ} \mathrm{C}$, at a heating rate of $10^{\circ} \mathrm{C} \mathrm{min}-1$. Thermal analysis provided the glass transition temperature $\left(T_{\mathrm{g}}\right)$, crystallization temperature $\left(T_{\mathrm{c}}\right)$ and melting temperature $\left(T_{\mathrm{m}}\right)$. The crystallinity value $\left(\chi_{\mathrm{c}}\right)$ was calculated by using the values of the endothermic melting peak using the Equation (1):

$$
\chi_{\mathrm{c}}=\frac{\Delta H_{\mathrm{m}}}{\Delta H_{\mathrm{m}}^{0}}
$$

where $\Delta H_{\mathrm{m}}$ is melting enthalpy, and $\Delta H_{\mathrm{m}}^{0}$ the melting enthalpy for polyethylene terephthalate, considered $140 \mathrm{~J} \cdot \mathrm{g}^{-1}$ [14].

The adhesion of the coating was evaluated by using the pull-off test according to the ASTM D4541 standard [15]. Dollies of $20 \mathrm{~mm}$ were glued on the plate coated with Huntsman Araldite 2000 glue; the cure occurred in a period of $24 \mathrm{~h}$. The equipment used was a De Felsko PosiTest AT-M (Ogdensburd, NY, USA). The tests were performed in triplicate.

Coating thickness was measured by using a digital layer thickness gauge on a ferrous base Digi-Derm Mitutoyo (Aurora, CO, USA). Ten measurements were collected on the coated steel.

The size distribution of the PET particles was performed by laser diffraction in the Mastersizer 3000 equipment (Worcestershire, UK). The obtained values were $D(4,3)$, which represents the average size distribution; $D_{\mathrm{v}}(10)$, which represents that only $10 \%$ of the particles were smaller than the displayed value; $D_{\mathrm{v}}(50)$, showing that $50 \%$ of the particles were larger, and $50 \%$ smaller than the determined value; and $D_{\mathrm{v}}(90)$, which reveals that $90 \%$ of the particles were below this value.

\subsection{Corrosion Resistance Evaluation}

Corrosion tests were performed using an Equilam salt spray chamber (Diadema, Brazil) in compliance with the ASTM B117 standard [12] for $500 \mathrm{~h}$. The solution used was $5.0 \mathrm{wt} \% \mathrm{NaCl}$ with $\mathrm{pH}$ between 6.5 and 7.2. A linear scratch was made on the coated steel with a tungsten carbide tool at an angle of $60^{\circ}$.

Electrochemical impedance spectroscopy was performed by using Metrohm AUTOLAB $302 \mathrm{~N}$ potentiostat/FRA (Utrecht, The Netherlands) at room temperature. The measurements were performed using a three-electrode electrochemical cell; a platinum foil was used as a counter electrode, a $\mathrm{Ag} / \mathrm{AgCl}_{\text {(sat) }}$ reference electrode was used, and the coated samples were employed as working electrodes. A polyvinylchloride (PVC) tube was affixed with silicone glue on the coated plate, delimiting the exposure area to $6.25 \mathrm{~cm}^{2}$, where the $3.0 \mathrm{wt} \% \mathrm{NaCl}$ solution was poured. The open circuit potential was measured for one hour or until stabilization. The EIS measurements were collected at the OCP after 1, 24, 192, 360, 480, and $576 \mathrm{~h}$ of immersion. The potential signal amplitude applied was $10 \mathrm{mV}(\mathrm{rms})$, and the frequency range analyzed was $10^{5}-10^{-2} \mathrm{~Hz}$. The data collected were analyzed by using the ZView2 software.

Evolution of the capacitance of the film was employed to measure the phenomena of water absorption since the presence of moisture modifies the dielectric constant of the polymer $[16,17]$. 
The ratio of the dielectric constant $(\varepsilon)$ of the coating was calculated using Equation (2) [18]:

$$
\varepsilon=\frac{C_{\mathrm{c}}}{\varepsilon_{0} A} L
$$

$\varepsilon_{0}$ is the dielectric constant of free space $\left(8.854 \times 10^{-12} \mathrm{~F} \mathrm{~m}^{-1}\right), A$ is the coating area and $L$ is the coating thickness.

The fraction of water volume of coating at saturation $\left(\varnothing_{\infty}\right)$ was calculated by using the Brasher and Kingsbury (BK) formula:

$$
\varnothing_{\infty}=\frac{\log C_{\infty} / C_{0}}{\log C_{t}}
$$

where $C_{\infty}$ is the coating capacitance at immersion time $t$ (determined from EIS data); $C_{0}$ is the initial coating capacitance and $C_{t}$ is the relative permittivity of the water. The parameters $C_{\infty}$ and $\varnothing$ are dependent on the immersion time [19].

\section{Results and Discussion}

\subsection{Characterization Results}

Figure 1 shows the PET powder produced from post-consumer bottles. The particles are heterogeneous in shape and size. More elongated and other equiaxial particles can be identified. Particle sizes have been calculated from measurement of particle areas using the IMAGEJ-win64 software. The PET powder presented a particle area between 430 and 51,200 $\mu^{2}$, and $90 \%$ of PET particles showed the size of $635 \mu \mathrm{m}$.

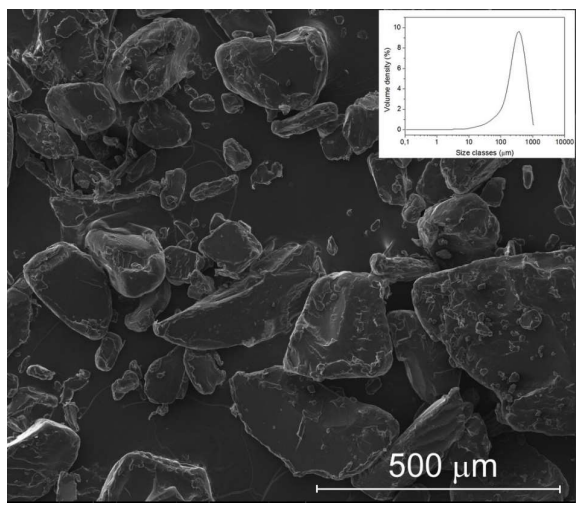

$\begin{array}{cc}\text { Parameter } & \text { Size }(\mu \mathrm{m}) \\ D(4,3) & 340 \\ D_{\mathrm{v}}(10) & 86.7 \\ D_{\mathrm{v}}(50) & 310 \\ D_{\mathrm{v}}(90) & 635\end{array}$

Figure 1. PET powder granulometric distribution.

Figure 2 presents the cross-sectional section of the coated steel obtained by using SEM analysis. The film is uniform and free of cracks and voids.

Figure 3 shows the FT-IR spectra of PET powder and coating, and Table 1 shows characteristic absorptions of functional groups present in PET powder and PET coating. The PET absorption band at $1715 \mathrm{~cm}^{-1}$ is attributed to vibrations of the carbonyl group of saturated esters; the bands at 724 and $871 \mathrm{~cm}^{-1}$ are due to the interaction of polar ester groups and benzene rings, vibration $=\mathrm{C}-\mathrm{H}$ out of the plane. The $1097 \mathrm{~cm}^{-1}$ band is associated with the stretching vibration mode of $\mathrm{C}-\mathrm{O}$ bonds and bands at $1242 \mathrm{~cm}^{-1}$ are associated to the specific absorption of the terephthalate group (OOC- $\left.\mathrm{C}_{6} \mathrm{H}_{4}-\mathrm{COO}\right)$. Bands related to the asymmetric deformation in $\mathrm{CH}_{2}$, at 1407 and $1018 \mathrm{~cm}^{-1}$, were identified [20-22]. At $2960 \mathrm{~cm}^{-1}$, absorption associated to the symmetrical stretch of the $\mathrm{C}-\mathrm{H}$ bond is observed, with a higher intensity for the PET powder than PET coating. Compared to the coating, the PET powder showed a broad band around $3600 \mathrm{~cm}^{-1}$ probably due to the water absorption. Notice that the FT-IR spectra of the powder and of the coating are very similar. The coating deposition treatment does not seem to affect the chemical structure of the polymer. 


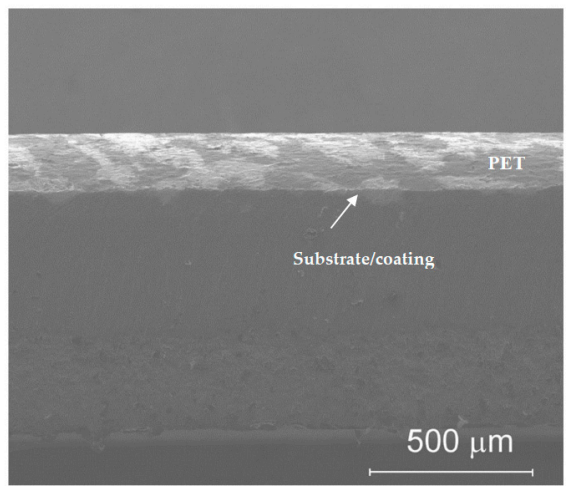

Figure 2. Cross-sectional view of PET coating.

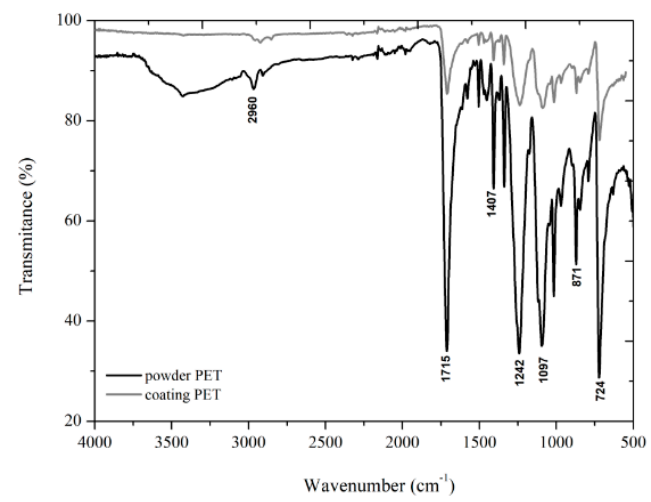

Figure 3. FTIR spectra of PET powder and PET coating.

Table 1. Characteristic absorptions of functional groups present in PET powder and PET coating.

\begin{tabular}{cc}
\hline Wavenumber $\left(\mathbf{c m}^{-\mathbf{1}}\right)$ & Functional Groups \\
\hline $3200-3600$ & $\mathrm{O}-\mathrm{H}$ \\
$2850-3000$ & $\mathrm{C}-\mathrm{H}$ aliphatic \\
$1715-1740$ & stretch $\mathrm{C}=\mathrm{O}$ unconjugated ketone, ester and carboxylic acid group \\
$1600-1690$ & stretch $\mathrm{C}=\mathrm{O}$ aromatic ketone and conjugated aldehydes \\
$1407,1018,1465$ & $\mathrm{CH}_{2}-$ \\
$1270-1097$ & ester group vibration \\
$1043-972$ & stretching of ether group $\mathrm{C}-\mathrm{O}-\mathrm{C}$ \\
871,724 & Vibration $=\mathrm{C}-\mathrm{H}$ benzene ring off plan \\
\hline
\end{tabular}

Figure 4 shows DSC results for PET powder and PET coating (removed from the mild steel substrate to carry out the analysis). Table 2 summarizes the thermal analysis results for PET powder and coating. Analyzing the $T_{\mathrm{g}}$ values, the onset values for PET powder and PET coating are very close being 73.8 and $72.8^{\circ} \mathrm{C}$, respectively, within the margin of error of the measurement that is $2{ }^{\circ} \mathrm{C}$. The glass transition temperature is the temperature at which the carbon-carbon bonds become more flexible. The PET coating is rigid at room temperature, since it is below $T_{\mathrm{g}}$.

The similar $T_{\mathrm{g}}$ values of powder and coating do not indicate significant damage in the reorganization of the polymer chain of the coating during deposition. As far as thermally sprayed PET on mild steels are concerned, Duarte et al. [9] reported that the $T_{\mathrm{g}}$ of coating was lower than that of the powder, which indicated a thermal degradation of the PET during the thermal deposition, decreasing its molar mass. In [9], the $T_{\mathrm{g}}$ value for the PET powder was $79{ }^{\circ} \mathrm{C}$, about $5{ }^{\circ} \mathrm{C}$ above the value obtained in this work. The glass transition temperature depends on the heating rate which is the same in this work and in reference [8]. In the case of the thermal spray technique, the polymer is subjected to high temperatures above $1000{ }^{\circ} \mathrm{C}$, above the degradation temperature of the PET which 
is about $450{ }^{\circ} \mathrm{C}$. Demirel [23] studied mound surface temperature in injection stretch blow molding (ISBM) of polyethylene terephthalate (PET) bottles for carbonated soft drinks (CSD) storage. The cited author reported the effect of mound surface temperature on $T_{\mathrm{g}}$ of PET bottles which varied between 58.3 and $59.4{ }^{\circ} \mathrm{C}$.

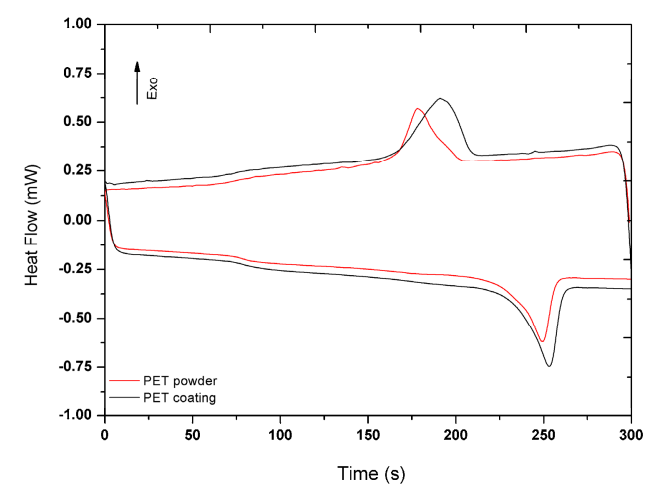

Figure 4. DSC results of PET powder and PET coating on mild steel.

Table 2. Glass transition and melting temperatures, and crystallinity of PET powder and PET coatings.

\begin{tabular}{ccccccccc}
\hline Sample & $\begin{array}{c}\text { Glass Transition } \\
\text { Temperature }\left(T_{\mathrm{g}}\right)\left({ }^{\circ} \mathrm{C}\right)\end{array}$ & $\begin{array}{c}\text { Crystallization } \\
\text { Temperature } \\
\left(T_{\mathrm{c}}\right)\left({ }^{\circ} \mathrm{C}\right)\end{array}$ & $\begin{array}{c}\Delta H_{\mathrm{c}} \\
\left(\mathrm{J} \mathrm{g}^{-1}\right)\end{array}$ & $\begin{array}{c}\text { Melting } \\
\text { Temperature } \\
\left(T_{\mathrm{m}}\right)\left({ }^{\circ} \mathrm{C}\right)\end{array}$ & $\begin{array}{c}\Delta H_{\mathrm{m}} \\
\left(\mathrm{J} \mathrm{g}^{-1}\right)\end{array}$ & $\begin{array}{c}\chi_{\mathrm{c}} \\
(\%)\end{array}$ & $\begin{array}{c}\text { Decomposition } \\
\text { Temperature } \\
\left(T_{\mathrm{d}}\right)\left({ }^{\circ} \mathrm{C}\right)\end{array}$ \\
\hline $\begin{array}{c}\text { PET } \\
\text { powder } \\
\begin{array}{c}\text { PET } \\
\text { coating }\end{array}\end{array}$ & 73.8 & 78.6 & 195.0 & 35.6 & 233.0 & 35.7 & 25.5 & 454.7 \\
\hline
\end{tabular}

The crystallization temperature of the coating showed an increase of $6.7 \%$ in relation to the powder, as seen in Figure 4 and Table 1. This phenomenon may have occurred due to the PET melting at $260{ }^{\circ} \mathrm{C}$ for application on the steel, and due to the slow cooling process, which provides time to recrystallization of part of the material. The $\chi_{c}$ values also confirm the crystallinity increase, being $25.5 \%$ for the powder and $31.7 \%$ for the coating. Takeshita et al. [24] studied the influence of cooling time on the physical properties of the polyester powder coating. They concluded that the cooling time influences the crystallinity values of the polymer and that the ratio between the cooling time and the degree of crystallinity is almost linear. In this sense, the increase in crystallinity of the PET coating was due to the cooling process of the coating deposition. Demirel [23] showed values of crystallinity of PET bottles similar to that found in this work, in the range from $21 \%$ up to $29 \%$. Melting temperatures for PET powder and coating were similar $\left(233\right.$ and $235^{\circ} \mathrm{C}$, respectively). Literature reports values of PET melting temperature in the range of $242-260^{\circ} \mathrm{C}[22,25]$.

PET degradation occurred at temperatures of 454.7 and $455.0{ }^{\circ} \mathrm{C}$ for powder and coating, respectively. As the PET reached $260{ }^{\circ} \mathrm{C}$ in the deposition process, degradation did not occur. Duarte et al. [9] reported degradation temperatures of $444{ }^{\circ} \mathrm{C}$ for PET powder and $437-446{ }^{\circ} \mathrm{C}$ for thermally sprayed PET coating.

Dry adhesion test was carried out by means of pull-off test. The detachment of the dolly occurred at the interface between the glue and the coating, at about $5 \mathrm{MPa}$. Based on these findings, we can assume that the adhesion strength is greater than $5 \mathrm{MPa}$. The value found for PET coating was compared with literature values for polyester powder coatings. As a result, we can observe in Table 3 that the adhesion values for the polyester family is very close to the value found in this work. 
Table 3. Thickness and adhesion for polyester and polyethylene terephtahalate.

\begin{tabular}{cccc}
\hline Samples & Thickness $(\mu \mathbf{m})$ & Adhesion $(\mathbf{M P a})$ & Reference \\
\hline Polyester & $291-294$ & $4.8-6.2$ & {$[24]$} \\
Carboxylate polyester resin (URALAC) & $50.0 \pm 5$ & $1.7-3.0$ & {$[26]$} \\
Saturated carboxylated polyester resin & $90.0 \pm 10$ & $4-6.8$ & {$[27]$} \\
Post-consumer polyethylene terephthalate & $65 \pm 5$ & $>5$ & This work \\
\hline
\end{tabular}

\subsection{Corrosion Resistance of PET Coated Steel}

\subsubsection{Results of Exposure of the Coating on Scratched Samples after $480 \mathrm{~h}$ in Salt Spray Chamber}

Salt spray results are shown in Figure 5 for up to $480 \mathrm{~h}$ of exposure in chamber.

The salt spray tests showed a reduced extent of coating delamination resulting from the scratch. No blisters where observed during the $480 \mathrm{~h}$ of immersion. As the test time increased, a marked increase in the corrosion of the carbon steel in the scratch area was observed. However, the cathodic front did not advance underneath the coating. No coating detachment was observed during exposure time of up to $480 \mathrm{~h}$.

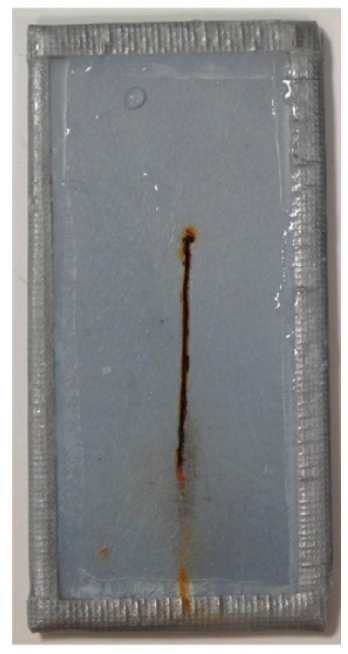

(a)

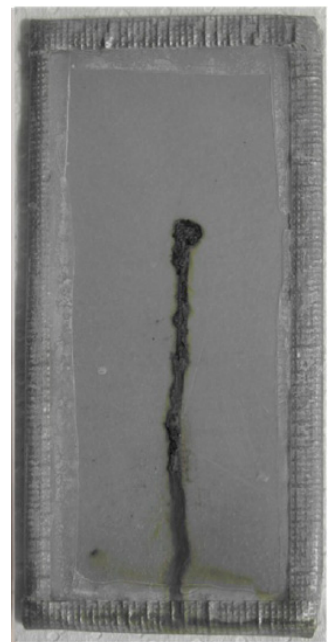

(b)

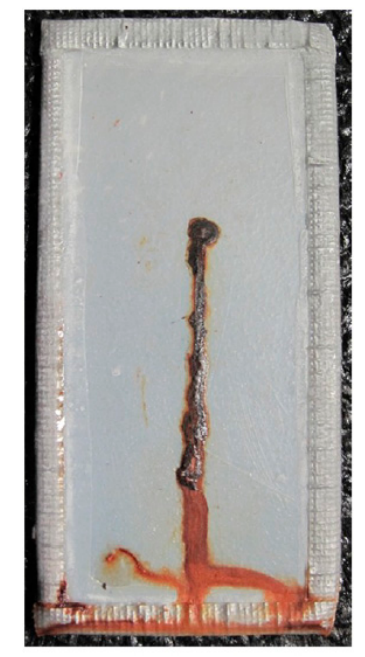

(c)

Figure 5. Photographs of PET coated steel after exposure for (a) 72, (b) 240, and (c) $480 \mathrm{~h}$ in a salt spray chamber.

\subsubsection{Electrochemical Impedance Spectroscopy (EIS)}

Figure 6 shows Bode diagram for PET coated steel in an aqueous solution of $\mathrm{NaCl}$ for immersion up to $576 \mathrm{~h}$. The phase angle curves are sometimes scattered, in particular between 10 and $100 \mathrm{~Hz}$ and around $0.1 \mathrm{~Hz}$, probably due to the relatively high impedance of the coating during immersion time. According to the impedance modulus diagrams (Figure 6a) the impedance values in the low frequency range (at about $0.01 \mathrm{~Hz},|Z|_{0.01}$ ) was high and almost stable as it ranged from $1 \times 10^{10}$ to $3 \times 10^{10} \Omega \mathrm{cm}^{2}$ throughout immersion time. A straight line with the slope close to -1 was observed in the Bode diagram, thus suggesting an almost capacitive behavior over a wide range of frequencies. A single time relaxation process was observed in the middle frequency range.

After $360 \mathrm{~h}$ of immersion, a decrease in impedance in the low frequency domain was observed, however, there is a trend for stabilization (Figure 7). The low frequency impedance was in the order of $1 \times 10^{10}-3 \times 10^{10} \Omega \mathrm{cm}^{2}$ during all immersion time, thus suggesting that the PET applied coating provided steel corrosion protection. The PET coating seems to be able to retard the direct contact between the corrosive medium and metal substrate. To better investigate the properties of the recycled PET coating, EIS data were fitted employing the equivalent circuit shown in Figure 7. According 
to [28,29], a $R_{\mathrm{e}}\left(Q_{\mathrm{c}} R_{\mathrm{p}}\right)$ was employed to fit the experimental spectra. $R_{\mathrm{e}}$ is the electrolyte resistance. The constant phase element, $Q_{\mathrm{c}}$, and the resistance, $R_{\mathrm{p}}$, where attributed to the dielectric properties and the pore resistance of the PET coating, respectively.

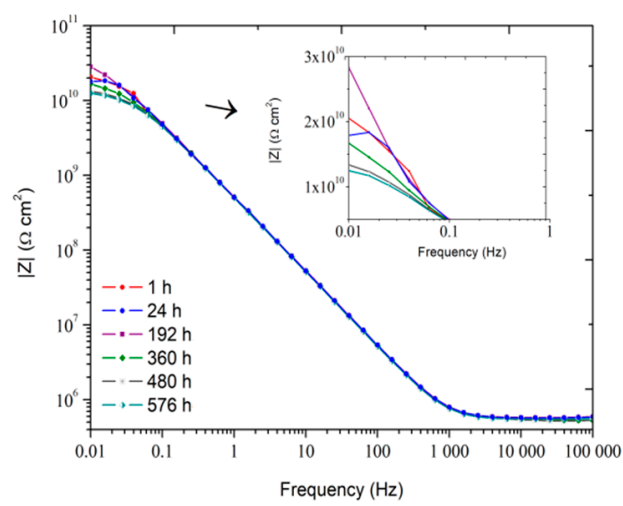

(a)

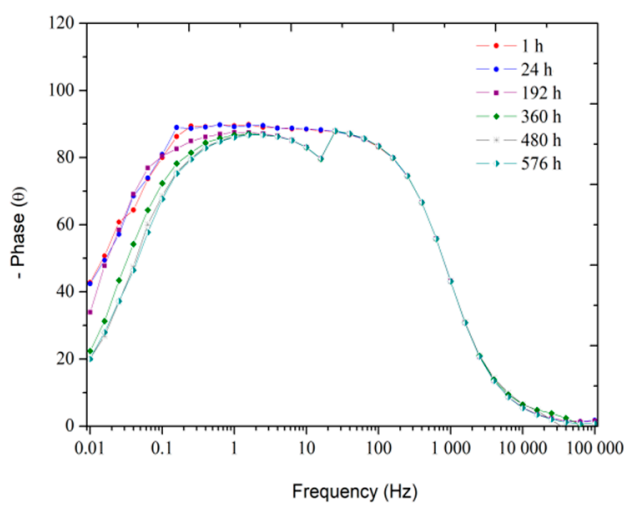

(b)

Figure 6. (a) Bode diagram of impedance modulus versus frequency for the PET coated steel in a saline environment for 1, 24, 192, 360, 480, and $576 \mathrm{~h}$, with amplification of low frequency region; (b) Bode diagram of phase angle versus frequency for the PET coated steel in a saline environment for 1, 24, 192, 360,480 , and $576 \mathrm{~h}$.

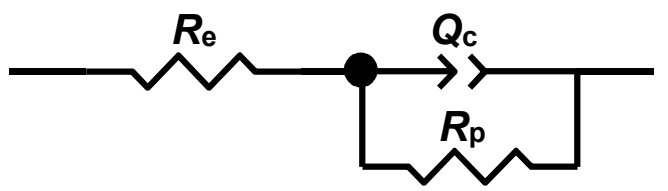

Figure 7. Equivalent circuit for EIS data of PET coated steel in $\mathrm{NaCl}$ solution.

Considering the results reported in Table 4, as the values of the ' $n$ ' exponent is about 0.98 during the whole immersion time, the pre-factor of the CPE named $Q_{\mathrm{c}}$ can be assumed as the coating capacitance. For this reason, from now on, the pre-exponential factors of the CPE will be considered throughout the paper as an acceptable approximation of the capacitance values during immersion time. Figure 8 shows the evolution of the normalized coating capacitance (respect to the initial capacitance value, $C_{t}=x / C_{t}=0$ ) during the first $24 \mathrm{~h}$ of immersion. Initially, a sharp increase in the normalized capacitance was observed, probably due to micropores formed in the coating which facilitated water permeation. After the first hours of immersion, the capacitance reached a sort of saturation, remaining stable at a value 1.12/1.14 times the initial capacitance. As far as the pore resistance is concerned, from Table 4 it is possible to observe that it decreased from $1.82 \times 10^{10}$ to $0.81 \times 10^{10} \Omega \mathrm{cm}^{2}$ after $576 \mathrm{~h}$ due to continuous immersion in the electrolyte, thus suggesting that the recycled PET coatings have excellent barrier properties.

In fact, the pore resistance $R_{\mathrm{p}}$ values of the investigated coatings are comparable or, in particular cases, highly compared to previously reported literature data (Table 5) related to polyester-based paints (derived from pristine materials). 
Table 4. Electrochemical parameters for PET coated steel in a saline medium.

\begin{tabular}{cccccc}
\hline Time (h) & $\boldsymbol{R}_{\mathbf{p}} \mathbf{1 0}^{\mathbf{1 0}}\left(\mathbf{\Omega} \mathbf{~ c m}^{\mathbf{2}}\right)$ & Error (\%) & $\begin{array}{c}\text { Pre-Factor of } \mathbf{Q}_{\mathbf{c}} \mathbf{~ 1 0}^{-\mathbf{1 1}} \\
\left(\mathbf{S ~ s} \mathbf{~ c m}^{\mathbf{2}} \mathbf{)}\right.\end{array}$ & Error (\%) & $\boldsymbol{n}$ \\
\hline 1 & 1.82 & 5.2 & 5.30 & 1.11 & 0.98 \\
24 & 1.78 & 3.77 & 5.25 & 1.35 & 0.98 \\
192 & 2.10 & 2.10 & 5.14 & 0.72 & 0.98 \\
360 & 1.09 & 1.69 & 5.25 & 0.83 & 0.98 \\
480 & 0.86 & 1.62 & 5.30 & 0.89 & 0.98 \\
576 & 0.81 & 1.62 & 5.34 & 0.90 & 0.98 \\
\hline
\end{tabular}

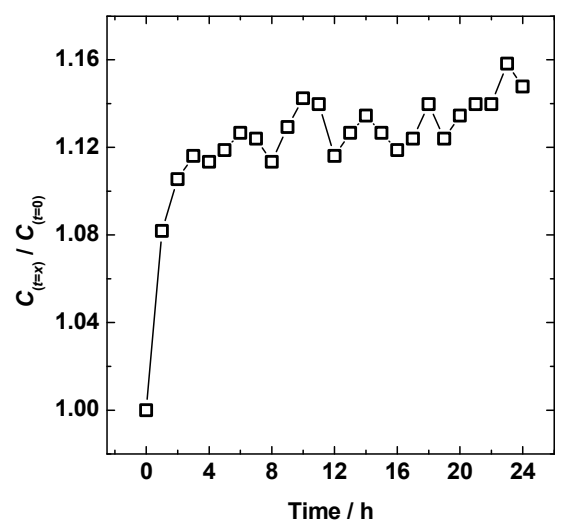

Figure 8. Capacitance versus immersion time of PET coated steel.

Table 5. $R_{\mathrm{p}}$ values for polyester from the literature in electrolytes of $3.0-3.5 \mathrm{wt} \%$ of $\mathrm{NaCl}$.

\begin{tabular}{ccccc}
\hline Samples & Thickness $(\mu \mathbf{m})$ & Time $(\mathbf{h})$ & $\boldsymbol{R}_{\mathbf{p}}\left(\boldsymbol{\Omega} \mathbf{c m}^{\mathbf{2}}\right)$ & Reference \\
\hline Polyester powder coating & $90 \pm 10$ & $0-500$ & $\approx 10^{8} \rightarrow 10^{5}$ & {$[27]$} \\
Polyester powder coating & $30 \pm 2$ & $24-1368$ & $\approx 10^{10} \rightarrow 10^{7}$ & {$[28]$} \\
Polyester powder coating & $45 \pm 3$ & $168-1200$ & $\approx 10^{7} \rightarrow 10^{4}$ & {$[30]$} \\
Polyester/epoxy powder coating & $45 \pm 3$ & $168-1200$ & $\approx 10^{8} \rightarrow 10^{5}$ & {$[30]$} \\
Polyester resin & $30-40$ & $0-720$ & $\approx 10^{7} \rightarrow 10^{4}$ & {$[31]$} \\
\hline
\end{tabular}

Relative permittivity of dry coating $\varepsilon_{\mathrm{d}}$ and fraction of water volume $\varnothing$ were calculated by Equations (2) and (3). The value of $\varepsilon_{\mathrm{d}}$ for PET coating was 5.0: this value is in accordance with relative permittivity reported in the literature to dry coating 3-8 [29,32,33]. The coating to be considered protective and water resistant must show the value of $\varnothing$ between $2.0 \%$ and $15.98 \%$, approximately [29,34]. The value of fraction of water volume estimated for the PET coating was 3.2\% after $24 \mathrm{~h}$ of immersion in $3.0 \mathrm{wt} \%$ $\mathrm{NaCl}$ solution.

\section{Conclusions}

The DSC results indicated no significant damage to the polymer produced by the mechanical deposition (press recycled).

The PET organic coating with a thin layer of $65 \mu \mathrm{m}$ presented good adhesion to the substrate, superior to $5 \mathrm{MPa}$, evaluated by using the pull-off test, as well as a high corrosion protection for carbon steel during long immersion times in the $\mathrm{NaCl} 3.0 \mathrm{wt} \%$ electrolyte; both of which are important characteristics for an anticorrosive organic coating. The polarization resistance of PET coated steel in a saline solution was $8.1 \times 10^{9} \Omega \mathrm{cm}^{2}$ after $576 \mathrm{~h}$ of immersion. The value of fraction of water volume absorbed was $3.2 \%$ indicating the excellent protective action of coating.

The PET organic coatings can be considered as an alternative, both for the PET recycling and for a new anticorrosive coating.

Wear evaluation of PET coating will be performed in further investigation. 
Author Contributions: Conceptualization, E.S., V.L., F.D. and M.F.; Methodology, E.S.; Validation, E.S., F.D., M.F. and F.C.; Formal Analysis, E.S., M.F. and F.C.; Investigation, E.S. and M.F.; Writing-Original Draft Preparation, E.S. and V.L.; Writing-Review \& Editing, E.S., M.F., F.D., F.C. and V.L.; Supervision, E.S.; Project Administration, E.S., F.D. and M.F.

Funding: This research was funded by Foundation CAPES (Coordination for higher Education Staff Development) (No. 88881.135023/2016-01).

Acknowledgments: The authors would like to sincerely thank the polymers laboratory of University of Trento.

Conflicts of Interest: The authors declare no conflict of interest.

\section{References}

1. $\quad$ Lins, V.F.C.; Branco, J.R.T.; Diniz, F.R.C.; Brogan, J.C.; Berndt, C.C. Erosion behavior of thermal sprayed, recycled polymer and ethylene-methacrylic acid composite coatings. Wear 2007, 262, 274-281. [CrossRef]

2. Le, L.; Mojtaba, M.; Chun, Q.L.; Dilan, R. Effect of corrosion and hydrogen embrittlement on microstructure and mechanical properties of mild steel. Constr. Build. Mater. 2018, 170, 78-90. [CrossRef]

3. Sienkiewicz, M.; Janik, H.; Borzędowska-Labuda, K.; Kucińska-Lipka, J. Environmentally friendly polymer-rubber composites obtained from waste tyres: A review. J. Clean. Prod. 2017, 147, 560-571. [CrossRef]

4. Çınar, M.E.; Kar, F. Characterization of composite produced from waste PET and marble dust. Constr. Build. Mater. 2018, 163, 734-741. [CrossRef]

5. Ramachandra, T.V.; Bharath, H.A.; Kulkarni, G.; Han, S.S. Municipal solid waste: Generation, composition and GHG emissions in Bangalore, India Review article. Renew. Sustain. Energy Rev. 2018, 82, 1122-1136. [CrossRef]

6. Plastics Europe. Available online: https://www.plasticseurope.org/application/files/5715/1717/4180/ Plastics_the_facts_2017_FINAL_for_website_one_page.pdf (accessed on 9 August 2018).

7. Shen, L.; Worrell, E.; Patel, M.K. Open-loop recycling: A LCA case study of PET bottle-to-fibre recycling. Resour. Conserv. Recycl. 2010, 55, 34-52. [CrossRef]

8. Awaja, F.; Pavel, D. Recycling of PET. Eur. Polym. J. 2005, 41, 1453-1477. [CrossRef]

9. Duarte, L.T.; Paula, E.M.; Branco, J.R.T.; Lins, V.F.C. Production and characterization of thermally sprayed polyethylene terephthalate coatings. Surf. Coat. Technol. 2004, 182, 261-267. [CrossRef]

10. Phetphaisit, C.W.; Namahoot, J.; Saengkiettiyut, K.; Ruamcharoen, J.; Ruamcharoen, P. Green metal organic coating from recycled PETs and modified natural rubber for the automobile industry. Prog. Org. Coat. 2015, 86, 181-189. [CrossRef]

11. Sanaee, Z.; Mohajerzadeh, S.; Zand, K.; Gard, F.S.; Pajouhi, H. Minimizing permeability of PET substrates using oxygen plasma treatment. Appl. Surf. Sci. 2011, 257, 2218-2225. [CrossRef]

12. ASTM B117 Standard Practice for Standard Practice for Operating Salt Spray (Fog) Apparatus; ASTM International: West Conshohocken, PA, USA, 2012.

13. ISO 9227-2017 Corrosion Tests In Artificial Atmospheres—Salt Spray Tests; ISO: Geneva, Switzerland, 2017.

14. Jayakannan, M.; Ramakrishnan, S. Effect of branching on the crystallization kinetics of poly(ethylene terephthalate). J. Appl. Polym. Sci. 1999, 74, 59-66. [CrossRef]

15. ASTM D4541 Standard Test Method for Pull-Off Strength of Coatings Using Portable Adhesion Testers; ASTM International: West Conshohocken, PA, USA, 2017.

16. Deflorian, F.; Fedrizz, L.; Rossi, S.; Bonora, P.L. Organic coating capacitance measurement by EIS: Ideal and actual trends. Electrochim. Acta 1999, 44, 4243-4249. [CrossRef]

17. Bacon, R.C.; Smith, J.J.; Rugg, F.M. Electrolytic resistance in evaluating protective merit of coatings on metals. Ind. Eng. Chem. 1948, 40, 161-168. [CrossRef]

18. Zhang, J.; Hu, J.; Zhang, J.; Cao, C. Studies of impedance models and water transport behaviors of polypropylene coated metals in $\mathrm{NaCl}$ solution. Prog. Org. Coat. 2004, 49, 293-301. [CrossRef]

19. Wang, H.; Zhou, Q. Evaluation and failure analysis of linseed oil encapsulated self healing anticorrosive coating. Prog. Org. Coat. 2018, 118, 108-115. [CrossRef]

20. Chen, Z.; Hay, J.N.; Jenkins, M.J. FTIR spectroscopic analysis of poly(ethylene terephthalate) on crystallization. Eur. Polym. J. 2012, 48, 1586-1610. [CrossRef] 
21. Chen, Z.; Hay, J.N.; Jenkins, M.J. The thermal analysis of poly(ethylene terephthalate) by FTIR spectroscopy. Thermochim. Acta 2013, 552, 123-130. [CrossRef]

22. Parvinzadeh, M.; Moradian, S.; Rashidi, A.; Yazdanshenas, M.E. Surface characterization of polyethylene terephthalate/silica nanocomposites. Appl. Surf. Sci. 2010, 256, 2792-2802. [CrossRef]

23. Demirel, B. Optimisation of mould surface temperature and bottle residence time in mould for the carbonated soft drink PET containers. Polym. Test 2017, 60, 220-228. [CrossRef]

24. Takeshitaa, Y.; Sawadaa, T.; Handaa, T.; Watanuki, Y.; Kudo, T. Influence of air-cooling time on physical properties of thermoplastic polyester powder coatings. Prog. Org. Coat. 2012, 75, 584-589. [CrossRef]

25. Guçlu, G.; Orbay, M. Alkyd resins synthesized from postconsumer PET bottles. Prog. Org. Coat. 2009, 65, 362-365. [CrossRef]

26. Mirabedini, S.M.; Kiamaneshb, A.A. The effect of micro and nano-sized particles on mechanical and adhesion properties of a clear polyester powder coating. Prog. Org. Coat. 2013, 76, 1625-1632. [CrossRef]

27. Puiga, M.; Cabedoa, L.; Graceneaa, J.J.; Jiménez-Morales, A.; Gámez-Pérez, J.; Suay, J.J. Adhesion enhancement of powder coatings on galvanised steel by addition of organo-modified silica particles. Prog. Org. Coat. 2014, 77, 1309-1315. [CrossRef]

28. Jegdić, B.V.; Bajat, J.B.; Popić, J.P.; Stevanović, S.I.; Mišković-Stanković, V.B. The EIS investigation of powder polyester coatings on phosphated low carbon steel: The effect of $\mathrm{NaNO}_{2}$ in the phosphating bath. Corros. Sci. 2011, 53, 2872-2880. [CrossRef]

29. Ding, R.; Jiang, J.; Gui, T. Study of impedance model and water transport behavior of modified solvent-free epoxy anticorrosion coating by EIS. J. Coat. Technol. Res. 2016, 13, 501-515. [CrossRef]

30. Mafi, R.; Mirabedini, S.M.; Naderi, R.; Attar, M.M. Effect of curing characterization on the corrosion performance of polyester and polyester/epoxy powder coatings. Corros. Sci. 2008, 50, 3280-3286. [CrossRef]

31. Ismail, L.; Ramesh, K.; Mat Nor, N.A.; Jamari, S.K.M.; Vengadaesvaran, B.; Arof, A.K. Performance of polyester/epoxy binder coating system-Studies on coating resistance, adhesion and differential scanning calorimetry. Pigment Resin Technol. 2016, 45, 158-163. [CrossRef]

32. Moreno, C.C.; Hernández, S.; Santana, J.J.; González-Guzmán, J.; Souto, R.M.; González, S. Characterization of water uptake by organic coatings used for the corrosion protection of steel as determined from capacitance measurements. Int. J. Electrochem. Sci. 2012, 7, 7390-7403.

33. Shreepathi, S.; Naik, S.M.; Vattipalli, M.R. Water transportation through organic coatings: Correlation between electrochemical impedance measurements, gravimetry, and water vapor permeability. J. Coat. Technol. Res. 2012, 9, 411-422. [CrossRef]

34. Fredj, N.; Cohendoz, S.; Mallarino, S.; Feaugas, X.; Touzain, S. Evidencing antagonist effects of water uptake and leaching processes in marine organic coatings by gravimetry and EIS. Prog. Org. Coat. 2010, 67, 287-295. [CrossRef]

(c) 2019 by the authors. Licensee MDPI, Basel, Switzerland. This article is an open access article distributed under the terms and conditions of the Creative Commons Attribution (CC BY) license (http://creativecommons.org/licenses/by/4.0/). 